\title{
Chapter 7 \\ Qualitative Migration Research: Viable \\ Goals, Open-Ended Questions, and Multidimensional Answers
}

\author{
Ewa Morawska
}

In the first part of this chapter, I review the epistemological premises informing qualitative investigations of international migration; identify the main research goals that can be pursued through this approach; briefly note relevant strategies of data collection and analysis; and suggest how best to present the results of qualitative studies. Drawing on the framework thus created, in the second part, I offer examples of the kinds of questions raised through the standard methods of qualitative investigation (interviewing, observation, and document analysis) in the examination of some of the existing and emerging problems that currently preoccupy scholars in the field of international migration studies. They include the decisionmaking process of potential cross-border travellers, immigrants' integration into the host society, and the role of super-diversity/multiculturalism in immigrants' everyday lives.

\subsection{The Main Premises, Goals, and Strategies of Qualitative Research}

Qualitative research in the social sciences in general and, of concern here, in investigations of international migration, traditionally aims to reconstruct people's everyday experience, both the inner and outer aspects of it, with the meanings those social actors attach to their situations and pursuits. It pays heed, in other words, to what the Polish sociologist Florian Znaniecki (1882-1958), under whose guiding star I was trained in social research methods at the University of Warsaw, called the "humanistic coefficient". Because social facts are created by social actors, Znaniecki

\footnotetext{
E. Morawska $(\bowtie)$

University of Essex, Colchester, UK

e-mail: emorawsk@essex.ac.uk
} 
insisted, the former can only genuinely be understood from the perspective of the latter (Znaniecki 1934). In order to take the humanistic coefficient in any given context into account researchers need to assume the perspective of the people whose lives are being examined. In short, they need what in the German tradition of verstehende or interpretative sociology is described as Einfühlung, empathy - quite literally the ability to sense what is going on in another person's mind or heart. Sociological research in the verstehende tradition represents a micro-level type of investigations into the social world conducted, however, with what C. Wright Mills referred to as the sociological imagination or, in his words, "the vivid awareness of in the relationship between personal experience and the wider world" (1959, p. 7). Qualitative research approaches the meaningful social action-the core concern, on Max Weber's account (1968), of sociological analysis - as inherently polymorphous and constantly assuming new forms as it unfolds, all of which should ideally be reflected in the collected data and its interpretation. Consequently, qualitative researchers are natural bricoleurs, "Jacks (and Jennies) of all trades", mixing and blending and, where necessary, reconfiguring a diverse range of methods and relevant insights (Denzin and Lincoln 2008, pp. 3-4) to render complex, multidimensional, and frequently "fuzzy" assessments of the examined situations. While this methodology of mixing, blending, and reconfiguring compounds the inherent diversity of the dynamic everyday functioning of social worlds and the human actors who (re)create them, qualitative analyses can, as I will argue, nevertheless facilitate the systematic pursuit of a variety of research goals and significantly expand our understanding of the social worlds we explore.

Qualitative research also focuses on the centrality of what Znaniecki (1934) called the "kinetic" or processual nature of social phenomena, which requires analytical attention to the temporal dimension of human lives. In his now classic essay, "Historical Sociology and Time" (1992), the American historical sociologist Ronald Aminzade distinguishes four dimensions of time whose effects should be considered by researchers approaching their object of study as processual rather than fixed: duration, pace, trajectory, and rhythm. Duration is relevant, for example, when the varying lengths of time an immigrant may have spent in the host country without authorization are likely to affect his or her prospects of mainstream employment. The differential impact of immigrants' sporadic vs. frequent journeys to their home country on the scope of their integration into the host society is a question of pace. For immigrants who came to the host country as children and completed their education there before entering the job market, the processes of socioeconomic integration are likely to differ markedly from those of their fellow nationals who arrived as grown-ups with occupational specializations acquired in the home country. These are questions of trajectory. The (ir)regularity with which immigrants experience everyday racial or religious rejection and discrimination, and the impact of that experience on the pace of their integration is a matter of rhythm.

Founded on the premise of the multi-dimensional and multi-form nature of human activities and the social world they create, which informs qualitative social science research, qualitative investigations render the representations of the analysed phenomena as inherently diverse, complex, and often "fuzzy". Adding to the 
amorphousness or under-determinacy of the outcomes of qualitative investigations are intended and unintended misrepresentations produced by the subjects of our investigations as well as the omissions and biases of the researchers themselves. Even with the critical assessment of the examined sources and the researcher's selfreflexive account of his/her impositions on the collected evidence (for good discussions of the what and how of self-reflexivity, see Denzin and Lincoln 2008; Lofland and Lofland 2006; Alvesson and Skoldberg 2012; Iosifides 2011, 2018), the representations of the social world and its human actors produced through qualitative investigations are, as most of the contemporary practitioners of this approach agree, unavoidably "gappy" and incomplete. Yet while the qualitative approach may not produce perfect, mirror-like representations of the phenomena it investigates, its practitioners are by no means abandoning the standards of scholarly practice. Rather, they are intellectually comfortable with their commitment to achieving the greatest possible measure of verisimilitude or the closest achievable approximation of their objects of study (this case has been persuasively argued, for instance, by Hammersley 1995, Atkinson 1990, and Madison 2012). Well executed qualitative studies, in our case of issues related to international migration, which achieve a high measure of verisimilitude generate rich, multi-layered, and nuanced accounts of the ways in which various aspects of the everyday immigrant experience evolve and unfold. The main strength of the qualitative approach in the social sciences lies in its ability to render more accurate representations of the actual life-worlds of those who inhabit them than purely quantitative surveys and analyses can.

As they become acquainted with the state of knowledge in the specific field of their investigation, the researchers should decide on the specific goal(s) that will guide their data collection and analysis. Charles Ragin (1994) has specified seven purposes informing social-science research: (i) identifying general patterns and relationships; (ii) testing and refining theories and guiding concepts; (iii) making predictions; (iv) interpreting culturally or historically significant phenomena; (v) exploring diversity; (vi) giving voice; and (vii) advancing new theories. On Ragin's account, qualitative research is conducive to the pursuit of three of his seven possible goals: the interpretation of culturally or historically significant phenomena, the exploration of diversity, and the lending of a voice.

In migration studies, the interpretation of culturally or historically significant phenomena is important, for instance, in assessing the transnational engagements of present-day immigrant-members of racial minorities in Europe, which are significant for their individual and collective self-esteem, or their likely impact on the immigrants' future integration into the mainstream of the host societies.

The qualitative exploration of diversity encompasses the probing of variations within phenomena or of deviations from patterns generally acknowledged in the relevant field of study. This might concern, for example, gender and/or racial subvarieties of the segmented assimilation modes generally governing immigrants' integration into the host society, or a sustained transnational investment of immigrants' grandchildren in their forbears' home country, which does not conform to the more usual gradual inter-generational weakening of this kind of engagement. 
The desire to lend a voice informs projects, which examine groups or phenomena that have been un(der)investigated and about which we know little or nothing at all - the most recent Syrian, Iraqi, and Afghan refugee settlers in Europe, for example, have not yet attracted much attention from social scientists. Often it is also the guiding principle in studies which aim to add more and/or new information to the already-existing stock of knowledge regarding particular groups or issues.

The testing and refining of theories and guiding concepts, by contrast, Ragin does not consider a suitable goal for qualitative research. Here I would disagree. In the case of international migration studies, the capacity of qualitative research to facilitate the testing and refining of theories and guiding concepts is well demonstrated, for example, by no fewer than five essays in the volume, Outsiders No More? Models of Immigrant Political Incorporation (2013), edited by Jennifer Hochschild et al. In our contributions, John Mollenkopf, Rafaela Dancygier, Monica McDermott, Michael Jones-Correa, and myself, each in our own way, challenge as too narrow and "ossified" and therefore revise the accustomed understanding of the ways in which immigrants are incorporated politically into the host society.

Alongside these four research goals qualitative research also has the potential to generate new research questions. The fieldwork conducted by Parvaneh Astinfeshan, a PhD student of mine at the University of Essex, is a case in point. Her research was originally devoted to the acculturation of sexual practices among Iranian immigrant couples - a surprisingly under-investigated dimension of newcomers' integration deserving of further study of the kind that lends a voice. The information her initial fieldwork generated led her to engage in a second round of data collection on a broader issue, namely, the continuities and changes in patterns of intimacy among these newcomers. Her conference papers on her findings have, in turn, inspired follow-up investigations of the mechanisms and challenges of acculturation in the field of intimacy and sexuality encountered by other immigrant groups.

All five research goals can, of course, be combined in a single project. Alongside the determination of the research goals that any given qualitative research project can hope to pursue, three more general issues need to be taken into consideration in the planning and execution of qualitative analyses. Firstly, one needs to decide whether to undertake a single- or multiple-case investigation. Most qualitative research projects are single-case studies - focusing, for example, on the mechanisms triggering the cross-border migration of Bangladeshis to the United Kingdom, or the civic-political acculturation of Polish migrants in Berlin who have settled in that city since their country joined the European Union in 2004. Single-cases studies can serve the pursuit of any of the named research goals and, if well executed, produce useful scholarly insights. Comparative multi-case investigations are more time- and energy-consuming, but also more rewarding in terms of the knowledge they generate. They can aim for a high level of complexity by including as many dimensions of the examined phenomena as possible. Alternatively, one can take the opposite approach, which tends to be more feasible for an investigator whose time and means are limited, and follow a simple (or even deliberately simplified) setup: a comparison of similar actors in different settings looking, for example, at the trajectories of acculturation of Indonesian immigrants in Amsterdam, Hamburg, and 
London; or of different actors in a similar setting looking, for instance, at multicultural orientations and everyday practices of Serbians, Turks, Poles, and Romanians in Vienna. They can be guided by one or more of the identified research goals (for an excellent discussion of different kinds of comparative analyses in qualitative investigations, see Charles Ragin's The Comparative Method [1987]). By way of encouragement to early career researchers let me note that qualitative comparative research can also be based on an original single-case investigation of one's own set in relation to comparative material gathered from other cases already covered in the secondary literature (provided, of course, that a sufficient amount of such evidence relevant to one's own topic exists).

The second consideration concerns the question of how to make sense of the evidence collected in qualitative investigations. A commonly used approach in qualitative research, which I recommend to the readers' consideration, holds that one can best answer the question of why social phenomena come into being, change, or persist, by demonstrating how they do so, that is, by showing how they have been shaped over time by various constellations of changing circumstances (Abrams 1982). In order to show how/why a social phenomenon evolves in a certain direction - rather than another - and assumes certain specific characteristics - rather than others - qualitative researchers reconstruct the constellation of specific circumstances that shaped these particular developments. Assuming we agree that the central focus of sociology - perhaps of the social sciences in general - lies on the ways in which society shapes individuals and individuals, in turn, shape society, an elegantly executed analysis of qualitative data should account for the relevant macroand meso-level societal influences by placing the orientations and activities of human actors within their immediate sociocultural surroundings centre stage. This brings me back to C. Wright Mills's emphasis on the need to bring "sociological imagination" to the interpretation of qualitative data.

In applying this precept in my own ethnographic research on international migration, I have derived the greatest cognitive gain from a multi-step assemblage of the constellation of factors, which shape the development(s) I am examining. I begin by identifying the macro-level (global, regional, national) circumstances - technological, economic, legal-political, sociocultural - that set the limits of the possible and the impossible within which individuals define and evaluate their situations, set their goals, and make decisions about the appropriate action/non-action. Next, I locate the relevant factors at the meso- (migrants' towns/villages and local communities) and micro-level (families and friends) that impact their preferences and actually available choices. I then reverse the direction of my analysis and look at the ways in which individuals creatively negotiate their situations in (re)defining their goals and pursuing their purposes, thus sustaining or, over time, transforming the broader economic, political, and sociocultural contexts in which they act.

The third consideration concerns the way in which the results of qualitative research are presented. Regardless of the specific research goals any given qualitative investigation may pursue - be it the interpretation of culturally or historically significant phenomena, the exploration of diversity, the lending of a voice, the testing or refining of existing theories and concepts, and/or the formulation of new 
research questions - and no matter whether it does so on the basis of a single-case or comparative analysis, the propositions resulting from qualitative research are best phrased in "soft" terms that emphasize the likelihood of any given conclusion rather than resorting to apodictic statements. Given the multi-faceted, fluid nature of the world we live in, and which qualitative investigations are to account for as faithfully as possible, the soft language of the propositions formulated in this genre of research is, in my opinion, yet another strength of this approach, not a limitation.

Focusing on three standard methods of qualitative research - interviewing, observation, and document analysis - I now want to illustrate how the premises governing forms of research in the social sciences guided by the "humanistic coefficient" work themselves out in practice by pointing to the sorts of questions we ought, to my mind, to be asking and, by implication, to the sorts of answers qualitative research on international migration accommodates.

\subsection{Questions and Answers in Qualitative Research on International Migration: Illustrations from the Current and Emerging Problem Agenda in the Field}

I have arranged my suggestions concerning the research questions I think we ought to be asking - and the caveats investigators, to my mind, need to bear in mind regarding the answers - by themes that feature among the existing and emerging problem agenda in migration studies: the contexts and considerations that shape migrants' decisions to undertake cross-border travel; the integration of immigrants into the host society; and the issue of super-diversity/multiculturalism in the everyday experience of immigrants. Given the importance of the decision to migrate or not to migrate for the subsequent life experience of those who move and those who stay, it is surprising how little attention qualitative researchers have paid to this issue (in marked contrast to the extensive quantitative examination of international population flows); hence my decision to focus on this theme. The integration of immigrants into the host society is a well-established and highly elaborated subject of research in migration studies and will therefore receive the most attention in this section. The issue of super-diversity/multiculturalism in the everyday lives of immigrants, by contrast, merits attention as the field of research that, in the course of the last decade, has made the most conspicuous advances in the field of migration studies, the recent increase in nationalist and exclusionary sentiments in several host countries notwithstanding.

I will not consider questions calling for simple "yes" or "no" answers - "do you hold the citizenship of your host-country?" etc. - and focus instead on inquiries that probe multi-dimensional aspects of the immigrant experience and are likely to be characterized by a range of diverse and often mutually attenuating or contradictory components. It is in the exploration of these constellations, after all, that qualitative 
research can make its core contribution. I will not engage, either, in the discussion of issues involved in critically assessing the reliability and validity of information gathered through interviewing, observation, and document analysis. The accepted procedures for dealing with these problems are well documented (see Bryman 2004, Ch. 18; also, Hammersley and Atkinson 2003, Ch. 5; on the critical assessment of official statistics, see Prewitt 2004).

\subsubsection{The Contexts and Considerations Shaping Migrants' Decision-Making Regarding Cross-Border Travel}

In my long practice as an immigration ethnographer I have benefited from initiating my investigations by asking my interviewees to narrate their life stories (on oral histories as a good method of gathering information in qualitative research, see Thompson 1978; Denzin 1989; Plummer 2001). This tends to put the interviewees at ease and provides researchers with valuable information regarding the basic facts about, and important events in, the respondents' lives. In keeping with the premises of interpretative sociology, it also gives room to the subjects' own interpretations of their life experiences, in our case, of the process that led to their decision to leave their home country and their choice of destination. Basic factual information aside, these accounts also offer initial insights into the relative significance of relevant events and circumstances for the decision to emigrate, and the sequence in which they impacted and shaped that decision. They can also reveal possible class, gender, and other socio-demographic differences, which then need to be followed up with the help of other sources and alternative research methods.

The individuals' accounts of the phase in which they prepared for migration should also be checked carefully for their narratives of how they performed social roles and adhered to, or deviated from, the expectations and obligations associated with those roles. Attention to the ways in which the individuals position their (e) migration-related activities in the context of their (trans)local social relations is also well worth the researchers' effort. Did they undertake those activities in interaction with others and against the backdrop of a general consensus, or did they proceed largely or in part on their own and met with opposition in their families and social circles, and what does this tell us about the hold of their social group over its members? (For a good qualitative account of migrants' experiences based on life stories told by Punjabi travellers to Europe, see Varghese and Rajan 2015; on the decision-making process among British-born Cypriots "returning" to Cyprus, see Teerling 2015).

The immigrants' life stories that open the investigation can take the form of an unstructured interview, allowing the narrators to follow their own priorities and concerns. Subsequent interviews may be conducted as semi-structured or structured face-to-face conversations (on different types of qualitative interviews and their respective advantages and limitations, see Denzin and Lincoln 2008; O'Reilly 2005). My preferred approach is a combination of both. I conduct these interviews 
with pre-prepared general themes in mind that correspond to the focus of my research and initially allow the respondents to elaborate on each theme on the basis of their perceptions of, and feelings about, these issues, before then proceeding to ask more specific questions on the matters in hand, some of which I have formulated in advance and some of which emerge over the course of the interview. Given that, like all important steps in life, decision-making about whether and, if so, where to migrate commonly involves ambivalence and contradictory sentiments and/or reasons, and that the underlying purpose of qualitative research is to reconstruct these complexities behind people's actions/non-actions as closely as possible, the investigator should pay careful attention to the indications of such indecision/hesitations in the respondents' life stories.

For researchers who intend to conduct their investigations in emigration regions and who are sufficiently familiar with the language and cultural codes guiding the conduct of those whose behaviour they want to study, observation is a good way of supplementing the information gathered through life stories and follow-up interviews (for the basic know-how regarding access to observation sites, different forms of observation, and ways of taking field notes, see Atkinson et al. 2001; Johnson 1975; O'Reilly 2005). Issues researchers are likely to want to focus on when undertaking such observation include the juxtaposition and evaluation of migration and non-migration in conversations and the underlying opinions and arguments; the ways in which the success or failure of returned migrants are referenced; and the extent to, and ways in, which migrants who have already reached their destination are treated as reliable sources of information and support by those contemplating migration themselves. In gauging the influence exerted by returnees on the decision of individuals to stay or migrate, their outward appearance, demeanour, material standard of living, lifestyle, and social status needs to be taken into account. Where applicable, the extent to which public statements by local political and/or religious leaders about the dis/advantages of migration are taken seriously by local residents in general, and potential migrants in particular, should also be observed.

When observing settings in the host country relevant to potential migrants and, especially, so-called foreign colonies and the formal and informal gathering places of mixed or ethnically distinct groups of immigrants, one needs to focus on the functioning of translocal social relations and cultural norms associated with membership in the respective social groups; on the émigrés' conversations about pending arrivals and the ways in which the arguments for and against their decision to migrate are discussed; and on evidence for the support they offer new migrants in the form of information and assistance with travel, housing and employment opportunities, as well as the expectations and caveats attached to such help (for excellent accounts, based on observation, of the migration experience of Polish and Caribbean cross-border travellers, respectively, see Irek 2014; Olwig 2007).

When it comes to the use of documentary sources, the crucial mainstay of research on the migration experience in its classic phase in the first half of the twentieth century, immigrant letters, have largely been replaced in the meantime by communication by telephone and via email and the internet (the most renowned multi-volume book based on immigrant letters is W. I. Thomas and Florian 
Znaniecki's The Polish Peasant in Europe and America, 1918-1920; for qualitative research on virtual modes of communication in general, see Hine 2000; Jones 1999; on immigrants' use of the web, see Crush et al. 2012; Leurs and Prabhakar 2018). Here too the researcher needs some familiarity with the investigated group's language and cultural codes of expression. Issues that can be probed by examining internet sites include the reasons identified by the participants as playing a role for them personally when considering the possibility of migration or deciding to migrate; the pros and cons they mention when discussing (e)migration in general and journeys to specific destinations in particular; and the information and support networks organized and relied upon by those who decide to migrate. Researchers should visit as many different sites as possible and do so several times, not only in order to cast the widest possible net when recording the issues that are of concern to the participants, but also in order to check how regularly specific problems and opinions feature and how prevalent they are.

Other documentary sources that can render information on the circumstances involved in the immigrants' decision-making processes regarding international travel and the ways in which they organize their movement, along with the dilemmas that accompany these experiences, include newspaper reports and letters to the editors; the TV and radio programmes of the émigrés' home society and their ethnic communities in the destination countries; novels about émigrés' lives; and, when it comes to assessing the significance and impact of role models for the migrants' decision-making processes, images of friends and acquaintances both in the home and host countries that illustrate their relative standard of living and general appearance and demeanour (for an example of the document analysis-based reconstruction of the cultural orientations of East European migrants to America in the late nineteenth and early twentieth centuries, see Morawska 1987). The information gathered from such documentary sources reflects a collective experience - not in the sense of being statistically representative, but in the sense that the experience is shared more or less commonly by members of the investigated (im)migrant group which the researcher then checks and checks again against individual life stories and interviews.

\subsubsection{The Immigrants' Integration into the Host Society}

Qualitative research on the integration of newcomers into the host society that is guided by the premises of interpretative sociology likewise tends to begin with the collection of the interviewees' life stories. In addition to basic information about their family histories, residential (re)locations, and the jobs they have had since their arrival in the host country, possible ups and downs in these developments and the ways in which they coped with these turns are of particular interest. Of similar importance are the personal and external factors they credit with an impact on their adaptation process, and the transformation (such as it is) of their previous worldviews and everyday practices in accordance with the cultural values and social 
expectations of the host society. These factors may include their human capital, individual initiatives and aspirations for the future, family life, social relations, residential locations, and occupational positions (Herbert's account [2008] of the ways in which South Asians put down roots in Leicester [UK] offers a good example for the effective use of immigrants' life stories in this context).

These autobiographical accounts will be of particular interest to qualitative researchers who pay attention to the processual nature of the ways in which immigrants adapt and, specifically, to the significant role that the sequence of events can play in émigrés' lives. An example from my own immigrant biography as compared to that of my same-age, same-urban-intelligentsia background friend highlights the relevance of this temporal dimension, while also illustrating an interesting aspect of diversity in the processes of newcomers' adaptation. We both came to America at roughly the same time as political refugees from communist Poland. While I spoke enough English to be offered a fellowship, which allowed me to undertake doctoral studies shortly after my arrival, my friend, who did not speak any English, had to postpone her graduate education plans and, instead, find work to support herself. Seven years went by, we both got married, but I already had my $\mathrm{PhD}$ and a job at a prestigious university while my friend, whose English by that time was passable, had not even enrolled in a graduate program yet. She then had two children (I did not have any) who preoccupied her completely for the next 8 years, and finally began her graduate studies 15 years after our arrival in America, at the same time as I was promoted to a full professorship. On graduation, she had a hard time finding academic employment and now works in a small community college in the Midwest. Our rather different trajectories were in no way caused by a disparity in our individual talents - my friend's intellectual potential when we were both in college in Warsaw was probably greater than mine - but resulted from the cumulative effects of the differing sequences of events in our respective lives as immigrants.

The accounts of their integration offered by immigrants when telling their life stories need to be probed further in follow-up interviews. Here it is again important to focus not only on basic factual data (their residential location, moves, and jobs since their arrival in the host country, and possible ups and downs along the way), but also on the impact which their residential location and occupational status has had on other (social and cultural) aspects of their assimilation, the extent to which they may or may not be developing a sense of belonging, and the ways in which their sociocultural adaptation affects their economic integration and vice versa. Especially when interrogating women and immigrants from racial or religious minorities it is important to ascertain whether they have experienced discrimination or prejudice, how they dealt with it, and how it has affected their self-perception and commitment to the host society.

Probing into what Milton Gordon (1964) called the intrinsic or symbolic dimension of immigrants' cultural assimilation, the qualitative researcher should inquire into the respondents' life orientations and cultural codes of perception and evaluation of their surroundings, both declared and applied in everyday practice, the transformations thereof since their relocation into the host society, and possible tensions between particular elements of these worldviews. Immigrants' cultural (mis)under- 
standings of the events/exchanges they encounter in their everyday lives are important aspects of their integration into the host society and should be carefully probed by the researcher. The process of my own assimilation in America was also marked by a series of misunderstandings as I began to put down cultural roots in my new country. An instructive example was my initial assumption that an African-American student in my introductory GTA class at Boston University (where I worked on my doctorate) came from Southern Italy - this was the only familiar label the East European me could assign to his light brown complexion; it is somewhat disconcerting that I subsequently failed to notice when, in the process of my acculturation into the American zero-sum system of racial classification, I stopped making such "mistakes." A good way to probe these issues is to ask the informants to enumerate the various walks of everyday life in which their own value judgments and cultural expectations, to their mind, correspond, or fail to correspond, to those of the host society. How has this changed since their arrival and which factors have influenced and effected this change? When communicating with, or visiting, their country of origin and its residents, to what extent and in what ways do they think of themselves as differing from their former fellow citizens and how would they explain this process of differentiation?

Standard inquiries into immigrants' cultural adaptation focus on their selfrepresentations; their familiarity with, and use of, the language of the host country at home, in their neighbourhood, at work, and at social events; their assimilation of the cultural customs and traditions, culinary conventions, dress codes, and public holidays of the host country and the frequency with which they themselves practise or adopt these customs. It is important that these issues are probed in an open fashion that allows informants to report multiple self-perceptions and diverse, even contradictory, practices of which researchers can then try to make sense. "Who are you?" can be a useful opening question, provided one encourages the respondents to mention all the identities they consider important. One might then follow up by asking what, specifically, in terms of their values, aspirations in life, and cultural preferences, to their mind, makes them Indian (or Pakistani, Nigerian, Polish, Romanian etc., as applicable). Conversely, have they acquired personal characteristics that they associate with the host country, and are they experiencing any tensions between specific orientations adopted from their home and host communities respectively?

As a next step, one might explore in greater depth the various elements that comprise immigrants' identity-sets and the specific contexts or situations in which particular elements come to the fore. How has the admixture of the elements within their identity-sets changed over time and what, in the opinion of the informants, has contributed to this transformation? (For a good discussion of immigrants' "multiple" and "divided" identities, see Spickard 2013; Leonard 2008). When respondents suggest that they identify with the host country, one should seek to ascertain which qualities, specifically, they identify with and whether there are any aspects of the public and private lifestyles characteristic of their new environment that remain alien to them (and, if so, why). 
When it comes to the important linguistic aspect of the integration of immigrants, informants are typically asked about the measure of their familiarity with the language of the host country and the contexts within, and the occasions on, which they use the language. Yet these basic questions hardly seem sufficient to gain an insight into the newcomers' inner state of being. In my own ethnographic investigations of the ways in which immigrants adapt to their host countries, I have found it much more rewarding to engage them in a conversation about the languages they feel comfortable using in various specific contexts: when speaking - which may differ depending on the interlocutor and the context - and writing or reading - which may differ depending on the nature and function of the text - when thinking or, for that matter, when crying or rejoicing. Here too, it is important to inquire about possible changes over time and the factors that affected them, and to ask how this impacts on their sense of belonging.

The forms of sociability engaged in by immigrants are another obvious point of interest. With whom do they associate, in what kinds of joint activities do they participate and how often do they do so, how have these encounters shaped their sense of belonging, and have the company they keep and/or the shared activities they engage in changed over time? Where immigrants live in multi-ethnic settings, it is a good idea to check whether their integration into the host society is facilitated by direct contact with, or immersion in, the dominant social group or by intermediaries. The recent Russian Jewish immigrants in Philadelphia are a case in point for the latter. They have come into contact with mainstream American institutions and "learn America" in large measure through the established American Jewish community in the city (see Morawska 2004).

Throughout, qualitative researchers will be keen to formulate questions that probe the multi-dimensionality of the processes by which immigrants adapt to the host society: do the economic, civic-political, social, and cultural aspects of their integration evolve synchronically or at varying paces? If they are out of step, why is this so and how do immigrants experience this asynchronicity? Middle-class Asian Indians in the United States, for example, have reportedly assimilated along two different trajectories - adhering to the mainstream in the economic realm yet maintaining an in-group ethnic path in the sociocultural sphere - and they apparently manage to avoid any significant tension between these two parallel paths of integration by deliberately keeping their relevant economic and sociocultural lives apart (Bhatia 2007; Dhingra 2007; Kurien 1998). For the members of other groups, however, the path to integration and the ways, in which it is experienced may be quite different. Given that humans are rarely able to shape all the aspects of their life into a coherent whole, qualitative researchers need to allow for discrepancies or even obvious contradictions in the accounts informants offer of their integration into the host society. The task lies in trying to understand the ways in which these discrepancies and contradictions are "lived" by the respondents.

Turning now to observation, it is important, when setting out to observe the ways in which the adaptation of immigrants to the host society is reflected in their verbal communication and social behaviour, to focus both on small groups and on larger social gatherings, both formal and informal, and to do so more than once, preferably 
on a number of occasions that vary in character. Alongside the ethnic composition of the groups it is important to take into consideration what the founder of microsociology, Georg Simmel (1903), called the "social geometry" of a group, i.e., the degrees of physical proximity and the regularity, duration or variability of interactions among particular people, and the kinds of bonds they generate. The type of food and/or drink served at these occasions, if any, requires reflection, especially in terms of the degree to which it is characteristic of either the home or the host country, as do the music played and/or the TV stations and/or other media watched, and the décor of the immediate surroundings. How prominently do topics relevant to the host and home societies, respectively, feature in conversations, and does the way in which national and local politics, and cultural issues are discussed vary, when they focus on the host society as opposed to the home country? Far from least, in which language(s) are these exchanges being conducted? Are particular issues discussed in a particular language, and why might participants be opting to mix the languages of their home and host countries? Do they use the word "we" to denote primarily either the home or the host society, or with which frequency and meaning(s) do they use it in both contexts? To the extent that an external observer is capable of reading it, one also needs to pay attention to the body language accompanying the immigrants' verbal expressions, bearing in mind that relevant codes and norms may differ between the home and host countries - one might think, for instance, of the contrast between the expressive-expansive style common among people from southern and eastern Europe and the constrained, self-controlled manner of the Northerners. Changes in body language may well reflect the degree to which newcomers have adapted to the host society. It is also possible that different settings evoke differing body languages, as Lieber and Levy (2013) have shown in their observation-based study of the adaptation of highly skilled Chinese settlers in Switzerland.

When trying to gauge the extent to which immigrants have internalized the cultural codes, which inform social interactions in the host society, one needs to take note of the style of conversation they adopt in ethnic as opposed to mixed social settings. As a native-born Pole and an ethnographer, I have invariably been intrigued and irritated roughly in equal measure by the unselfconsciously confrontational style displayed by many of my fellow East European immigrants in debates, in the United States and Europe alike, which is so roundly at odds with the "smoothedover", compromise-seeking mode of discussion generally practised in the West. This deeply ingrained confrontational style, founded on the premise that I must be an imbecile if we disagree and my interlocutor is right, extends even to topics as harmless as the weather forecast: if I say that it will rain tomorrow, my partner in conversation may well raise his or her voice and shout, "no, there will be sunshine!" This approach results in no small measure from the fact that the term "compromise" has a distinctly negative connotation in the Slavic languages, suggesting a lack of moral fortitude on the part of the person or group willing to compromise. When interviewing or observing East European immigrants one would therefore focus both on the extent to which they continue to maintain the more confrontational style to which they are accustomed or, alternatively, have adopted a less confrontational style more suited to their host society, and on the ways in which this may vary 
across a range of sociocultural contexts and encounters. It could be, of course, that the respondents' very concept of compromise has also changed in the course of their integration.

The range of documents that can usefully be analysed in this context does not differ substantially from those worthy of consideration when examining the crossborder migration process. Internet communication, reports and letters to the editor in foreign-language newspapers, TV and radio programmes, and novels about émigrés' lives reveal a good deal of information about various aspects of the process by which immigrants adapt to their host country. (I omit from this discussion, though qualitative researchers obviously need to examine them carefully, the official "bookkeeping" documents such as national and local censuses, relevant labour and welfare statistics and data detailing the residential concentration, demographic profile, economic position, and civic status of foreign-born residents). One should certainly examine how varying opinions about the host country's economic and legal-political system, its people and culture, on the one hand, and the various pursuits and achievements of the immigrants, on the other, are articulated on various websites, while also noting the frequency with which differing viewpoints are expressed and the responses they precipitate. The same goes for media and literary reports as well as immigrants' self-representations, where particular attention is merited both to the ways in which the term "we" is used and to the loci immigrants associate with their aspirations in life. All the while, researchers must continue to bear in mind that the process by which immigrants adapt to their host country is always multi-layered. Different dimensions of their lives (the economic, political, social, and cultural) may not be evolving synchronically and the trajectory of their integration may be non-linear, taking (re)turns and twists due to specific changes in their personal lives or political developments in their home or host countries.

It is also a good idea to encourage immigrant informants to show photographs of themselves, their families and their living environments both in the countries of origin and destination. These can be compared over a number of years to discern possible changes in individuals' appearance and demeanour and their environment on which one should then ask the respondents to comment.

Documents related to the activities of associations formed by immigrant groups, such as minutes of their meetings, membership lists, appeals issued, election records, etc. are also a valuable source for research on the integration of immigrants. What do these associations hold in common and what distinguishes them, in terms of their declared purposes and organization, how might this change over time, and (how) do their operations differ from those of comparable mainstream organizations in the host society? What contacts - civic-political, charity-related, or connected to inter-faith initiatives or cultural events - do the groups maintain with institutions and individual representatives of the host society, how regular, frequent and durable are these contacts? How many immigrants participate in the group's activities and what is their socio-demographic profile? (The study of the Italian ethnic press by Deschamps [2011] and Garapich's [2016] examination of the role ethnic media play 
in the process by which Polish immigrants in London simultaneously adapt to the host society and maintain ties to their home country are good examples of the use of document analyses in qualitative investigations).

\subsubsection{Immigrants' Experience of Super-Diversity/ Multiculturalism}

Multiculturalism, typically defined as "the recognition of difference" within the public sphere of "laws, policies, democratic discourses and the terms of a shared citizenship" (Modood 2007: 2), has been a matter of intense debate among social scientists for the last two decades. Together with its companion concept "superdiversity" - a term coined by Steven Vertovec (2007) to denote the increasing ethnoreligious diversification of contemporary societies - the concept of multiculturalism has recently also entered the field of international migration studies. While political scientists conceive of it more as a set of policies and legal provisions regarding the entitlements of different groups, qualitative research in migration studies approaches it primarily in terms of the ground-level experience of people's everyday lives. Quite a few studies of multiculturalism "from above" have already accrued, but the investigation of multiculturalism "from below", as experienced on an everyday basis, is something of a newcomer on the academic stage (see, for example, Wise and Velayutham 2009; Vertovec 2011).

I propose to define ground-level multiculturalism as consisting of three dimensions conceived in terms of degrees rather than present-absent attributes: (i) the forms and regularity of neutrally civil in the least and, at best, openly friendly intergroup contacts; (ii) representations of group differences as more horizontal than vertical arrangements; and (iii) a negotiatory rather than head-on confrontational mode of inter-group conflict resolution. How multiculturalist one's views and practices are in any given situation may vary according to the specific circumstances. The same holds true of the degree to which each of these three factors may be at play in any given context. Interview questions probing the multiculturalism of immigrants' orientations and practices - gauging, for instance, their attitudes towards generalized "others" and members of specific groups, the forms and frequency of their contact with them, the measure of familiarity and intimacy involved in these contacts, their participation in other groups' festivities and adoption of their culinary conventions, and their opinions about members of other groups holding public office (take the election of Sadiq Khan as mayor of London in May 2016) therefore need to be designed in a manner that allows for ambiguity, flexibility, and discrepancies in the reported sentiments and activities, and must inquire carefully into the situational dynamics of the specific multicultural engagements. 
Immigrants' possibly multicultural modes of integration into the host society could also be an interesting venue of investigation for a qualitative researcher. This line of inquiry would involve questions-as above, open-ended and inviting equivocal statements and uncertainty -about their symbolic identification with plural national/ethnic/religious groups resident in the host society and their traditions; about the internalization and practice of extrinsic (language, customs) and intrinsic (value-orientations, normative expectations, beliefs) components of the cultures of other national/ethnic-religious groups resident in the host society; regular social engagement with members of other national/ethnic/religious groups resident in the host society in formal, semi-formal, and/or informal settings including neighbourhood public places such as streets, shops, pubs, and eateries; workplaces, kindergartens and schools; homes and gardens; and civic commitment to/responsibility for the well-being of the body politic of several national/ethnic/religious communities resident in the host society.

Observation in this field would focus especially on immigrants' engagement of, and opinions about, national, ethnic and/or religious groups other than their own and the one that is dominant in the host country. One would pay attention, for instance, to the ethnic composition of the social gatherings the immigrants in question attend and the forms of interaction between them and the members of other groups they meet there, looking not least at the body language (noting measures of physical proximity and verbal intimacy); and one would carefully monitor topics of conversation among them, paying special attention to the models of a "good society" and "good legal regime" they espouse and their assessment of the measure of civic tolerance and respect for human rights afforded by the status quo in the host country in general and their own locality in particular. Should the way in which these issues are discussed and opinions are expressed differ between meetings attended exclusively by the immigrants in question and mixed meetings, it is important to take careful note of these differences. Familiarity with, and enjoyment of, the cultures of other groups (food, music) and their members, whether expressed verbally or in practical terms, should also be registered, since they reflect multicultural modes of adaptation to the host country.

The documentary sources likely to be of use in this context are again largely the same as before: internet communications, personal and group photographs, foreignlanguage newspapers, TV and radio programmes, novels about immigrant lives, and the records of relevant organizations. Here too, the principal focus would be on the presence (or absence) of groups or representatives of groups other than those of the immigrants in question themselves or the group that is dominant in the host country, the manner of their portrayal, and the extent to, and ways in, which it changes over time. 


\subsection{Conclusion}

Following a review of the basic epistemological premises of, and different strategies of research conducted in, the verstehende or interpretative tradition in social research, I have offered some examples of the sorts of questions and answers qualitative investigations of the experience of cross-border migration can raise and generate. These examples reflect the current agenda of migration studies and my own concerns and predilections and obviously do not constitute an exhaustive or mandatory list. They are meant as heuristic guideposts for the whats and hows of qualitative research in this field. If I were to offer any further advice to students interested in undertaking qualitative studies of migration-related phenomena, I would suggest that, when planning and designing their projects, they familiarize themselves with the research strategies and types of questions raised by scholars of migration whose training and expertise differ from their own. This would allow sociologists to gain new and useful insights from studies of the migrant experience conducted by anthropologists, social psychologists, historians, and/or urban geographers and might stimulate mutual cross-disciplinary engagement between all of them - thus energizing the debates within the field of migration studies in general.

\section{References}

Abrams, P. (1982). Historical sociology. Somerset: Open Books.

Alvesson, M. A., \& Skoldberg, K. (2012). Reflexive methodology: New vistas for qualitative research. London: Sage.

Aminzade, R. (1992). Historical sociology and time. Sociological Methods \& Research, 20(4), 456-480.

Atkinson, P. (1990). The ethnographic imagination. London: Routledge.

Atkinson, P., et al. (Eds.). (2001). Handbook of ethnography. London: Sage.

Bhatia, S. (2007). American karma: Race, culture, and identity in the Indian diaspora. New York: New York University Press.

Bryman, A. (2004). Social research methods. Oxford: Oxford University Press.

Crush, J., et al. (2012). Diaspora on the web: New networks, new methodologies. In C. VargasSilva (Ed.), Handbook of research methods in migration (pp. 345-365). Cheltenham: Edward Elgar.

Denzin, N. (1989). Interpretive biography. Newbury Park: Sage.

Denzin, N., \& Lincoln, Y. (Eds.). (2008). The landscape of qualitative research. London: Sage.

Deschamps, B. (2011). The Italian ethnic press in a global perspective. In G. Parati \& A. J. Tamburi (Eds.), The cultures of Italian migration. Diverse trajectories and discrete perspectives (pp. 75-94). Lanham: Fairleigh Dickinson University Press.

Dhingra, P. (2007). Managing multicultural lives: Asian American professionals and the challenge of multiple identities. Stanford: Stanford University Press.

Garapich, M. (2016). London's Polish borders. Stuttgart: Ibidem Verlag.

Gordon, M. (1964). Assimilation in American life. New York: Oxford University Press.

Hammersley, M. (1995). Ethnographic principles in practice. London: Routledge. 
Hammersley, M., \& Atkinson, P. (2003). Ethnography: Principles in practice. New York: Routledge.

Herbert, J. (2008). Negotiating boundaries in the city. Migration, ethnicity, and gender in Britain. Aldershot: Ashgate.

Hine, C. (2000). Virtual ethnography. London: Sage.

Hochschild, J., et al. (Eds.). (2013). Outsiders no more? Models of immigrant political incorporation. New York: Oxford University Press.

Iosifides, T. (2011). Qualitative methods in migration studies: A critical realist perspective. Farnham: Ashgate.

Iosifides, T. (2018). Epistemological issues in qualitative migration research: Self-Reflexivity, objectivity and subjectivity. In R. Zapata-Barrero \& E. Yalaz (Eds.), Qualitative research in European migration studies (pp. 93-109). Cham: SpringerOpen.

Irek, M. (2014). Circular travels: A site-less ethnography of an informal trading routes. https:// www.isca.ox.ac.uk/fileadmin/ISCA/JASO/2014/Irek . Accessed Nov 2016.

Johnson, J. (1975). Doing field research. New York: Free Press.

Jones, S. (1999). Doing internet research. London: Sage.

Kurien, P. (1998). Becoming American by becoming Hindu: Indian Americans take their place at the multicultural table. In R. S. Warner \& J. G. Wittner (Eds.), Gatherings in diaspora: Religious communities and the new immigration (pp. 37-70). Philadelphia: Temple University Press.

Leonard, K. I. (2008). Hyderabadis abroad: Memories of home. In P. Raghuram, A. K. Sahoo, B. Maharaj, \& D. Sangha (Eds.), Tracing an Indian diaspora: Contexts, memories representations (pp. 257-270). London: Sage.

Leurs, K., \& Prabhakar, M. (2018). Doing digital migration studies: Methodological considerations for an emerging research focus. In R. Zapata-Barrero \& E. Yalaz (Eds.), Qualitative research in European migration studies (pp. 247-266). Cham: SpringerOpen

Lieber, M., \& Levy, F. (2013). When you look Chinese, you have to speak Chinese: Highly skilled Chinese migrants in Switzerland and the promotion of a shared language. In P. Spickard (Ed.), Multiple identities. Migrants, ethnicity, and membership (pp. 134-162). Bloomington: Indiana University Press.

Lofland, J., \& Lofland, L. (2006). Analyzing social settings: A guide to qualitative observation and analysis. Belmont: Wadsworth.

Madison, S. (2012). Critical ethnography: Method, ethics, and performance. Thousand Oaks: Sage.

Mills, C. W. (1959). The sociological imagination. Harmondsworth: Penguin.

Modood, T. (2007). Multiculturalism. London: Verso.

Morawska, E. (1987). Sociological ambivalence: The case of East European peasant-immigrant workers in America, 1890s to 1930s. Qualitative Sociology, 38(3), 225-250.

Morawska, E. (2004). Exploring diversity in immigrant assimilation and transnationalism: The case of Poles and Russian Jews in Philadelphia. International Migration Review, 38(4), 1372-1412.

O’Reilly, K. (2005). Ethnographic methods. London: Routledge.

Olwig, K. F. (2007). Caribbean journeys: An ethnography of migration and home. Durham: Duke University Press.

Plummer, K. (2001). Documents of life 2. An invitation to a critical humanism. London: Sage.

Prewitt, K. (2004). The census counts, the census classifies. In N. Foner \& G. Fredrickson (Eds.), Not just black or white (pp. 144-164). New York: Russell Sage.

Ragin, C. (1987). The comparative method. Berkeley: University of California Press.

Ragin, C. (1994). Constructing social research. Thousand Oaks: Pine Forge Press.

Simmel, G. (1903). Soziologie des Raumes, in ibid, Aufsaetze und Abhandlungen 1901-1908, vol. 1, translated into English and reprinted as 'The Sociology of Space' In: D. Frisby, \& M. Featherstone (Eds.), Simmel on culture (pp. 137-169). London: Sage. 1997.

Spickard, P. (Ed.). (2013). Multiple identities. Migrants, ethnicity, and membership. Bloomington: Indiana University Press. 
Teerling, J. (2015). The "return" of British-born Cypriots to Cyprus: A narrative ethnography. Brighton: Sussex Academic Press.

Thomas, W. I., \& Znaniecki, F. (1918-1920). The Polish peasant in Europe and America, vols. III. Chicago: University of Chicago Press. vols. III-V Boston: Badger Press.

Thompson, P. (1978). The voice of the past: Oral history. Oxford: Oxford University Press.

Varghese, V. J., \& Rajan, S. I. (2015). Migration as a transnational enterprise: Migration from Eastern Punjab and the question of social licitness. In S. I. Rajan, V. J. Varghese, \& A. K. Nanda (Eds.), Migration, mobility and multiple affiliations. Punjabis in a transnational world (pp. 172-204). Cambridge: Cambridge University Press.

Vertovec, S. (2007). Super-diversity and its implications. Ethnic and Racial Studies, 30(4), $1024-1054$.

Vertovec, S. (Ed.). (2011). Anthropology of migration and multiculturalism. London: Routledge.

Weber, M. (1968). Economy and society: An outline of interpretive sociology. New York: Bedminster Press.

Wise, A., \& Velayutham, S. (Eds.). (2009). Everyday multiculturalism. Basingstoke: Palgrave Macmillan.

Znaniecki, F. (1934). The method of sociology. New York: Farrar and Rinehart.

Open Access This chapter is licensed under the terms of the Creative Commons Attribution 4.0 International License (http://creativecommons.org/licenses/by/4.0/), which permits use, sharing, adaptation, distribution and reproduction in any medium or format, as long as you give appropriate credit to the original author(s) and the source, provide a link to the Creative Commons license and indicate if changes were made.

The images or other third party material in this chapter are included in the chapter's Creative Commons license, unless indicated otherwise in a credit line to the material. If material is not included in the chapter's Creative Commons license and your intended use is not permitted by statutory regulation or exceeds the permitted use, you will need to obtain permission directly from the copyright holder.

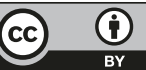

